\title{
Away from Her? Sarah Polley's Screen adaptation of Alice Munro's “The Bear Came Over The Mountain"
}

\begin{abstract}
Away from Her (2006), Sarah Polley's debut as director and screenwriter, based on Nobel Prize winner Alice Munro's "The Bear Came Over the Mountain," stands out as a paradigmatic case of artistic adaptation. In the process of adapting the story to the screen, this Canadian actress-turned-filmmaker manages to use innovative cinematic techniques, such as the 'space-off' and 'reversal,' to convey her feminist interpretation of Munro's cryptic text. Though her scripted dialogue shows a high degree of similarity to Munro's text, Polley avoids mimicry and successfully reproduces the core of the story in the new medium. It is as if she knew beforehand that if she wants to get closer to an artistic adaptation of a text by one of Canada's most renowned writers, she must remain somehow Away from Her.
\end{abstract}

Key words

Canadian cinema; images of affection; space-off; author-based cinema; screen adaptation of a literary text; Hollywood melodrama

"I feel as if I'm sailing into darkness."

Iris

"Half the time I wander around looking for something which I know is very pertinent. But then, I can't remember what I'm looking for ... once the idea is lost, everything is lost and I have to wander around trying to figure out what it was that was so important earlier." 
Based on Alice Munro's "The Bear Came Over the Mountain," a story first published in the December 27, 1999 edition of The New Yorker, Away from Her is Canadian actress Sarah Polley's feature film debut as director and screenwriter. A highly acclaimed actress, one of those young Canadian actors to have made it into Hollywood ${ }^{1}$ (The Sweet Hereafter and My Life Without Me), in 2006, this is, barely six years after the publication of Munro's story, Polley faced a major challenge in her still then fledging career as director: adapting a complex text by one of Canada's most iconic writers, very recently awarded the Nobel Prize of Literature.

Why did she decide to embark on such a difficult project? Polley tries to explain it in the preface for the film tie-in edition. She first read Munro's story on a plane from Iceland, ${ }^{2}$ where she had been acting together with Julie Christie on the set of No Such Thing. Polley was so immediately captivated by Munro's story that she read it, as she herself confessed, "about 10 times" (2007: vii).

Cinematizing a text with such a disruptive chronology and so many silences and non sequiturs is far from being an easy endeavour, much less for an actressturned-filmmaker's debut. A filmic adaptation of a literary work is very unlikely to succeed if it veers towards mere mimicry. What is at stake is much more complex than a slavish process of formulaic transferences. Far from being so, the original story, with its core meanings and narrative strategies, must be created anew in a different medium, whose potential may be expanded by some of its inherent techniques yet limited by other restrictions.

Traditionally, however, adaptations have been always measured by one single criterion, fidelity, the only marker of their success as adaptations being their degree of faithfulness to the original. As Brian MacFarlane rightly argues in his preface to Novel to Film "discussion of adaptation has been bedeviled by the fidelity issue" (1996: 8).

Regrettably so, this polarized debate has blinded a part of the audience to the real merits of some meta-adaptive endeavours. One of them is the personal way in which the adapter chooses to interpret the source text. Munro's story poses a considerable challenge here because of the many silences and ambiguities the story is riddled with. Certainly, the risks of failure, given all these numerous complexities, are rather high.

For an author-based, Canadian product, ${ }^{3}$ however, the film adaptation turned out to be a complete success. Julie Christie not only received an Oscar nomination for her outstanding performance as Fiona but she also garnered a series of prestigious awards, amongst them the Best Actress Golden Globe and the Screen Actors Guild's Best Actress Award. Sarah Polley's screenplay also received an Oscar nomination for Best Adapted Screenplay.

Polley's film works indeed as a paradigmatic case of artistic adaptation: first, she opts for shooting new scenes to add more dramatic intensity to the condition of Fiona's disoriented mind after the first symptoms of her neurodegenerative disease start to surface; second, she resorts to the technique of dissolve to juxtapose episodes separated by distant time and space contexts, thus rendering a visual 
equivalent of Munro's narrative disruptions whilst framing the story in the subjective time of Fiona's mind; finally, she tries to reframe the two main characters to cinematize their reversal of roles and reconstructs the "space-off" to translate to the screen both Fiona's attempt to search for new sites of self-representation and Grant's regressive spirals once Fiona starts to treat him like a stranger.

In her overture to the story, Munro begins depicting the life of a sexagenarian couple, now retired to a cozy cottage on the shore of a lake in Ontario. After fortyfour years of marriage, the couple seems to stand out as an example of marital bliss: they share the household chores (usually before supper, "one of them made the drinks and the other the supper"), they talk about Grant's work ("he was writing a study of legendary Norse wolves and particularly of the great Fenris wolf who swallows up Odin at the end of the world), and, their advanced age notwithstanding, they still enjoy their moments of "physical sweetness" (2010: 455). However, as soon as the first symptoms of Fiona's memory lapses start to surface, Grant (Gordon Pinsent) has to shift his role to that of Fiona's caretaker.

Yet Munro's non-linear structure, which mirrors the lapses and time dislocations commonly associated with Alzheimer's disease, poses a challenge for screen adaptation. Munro's flashbacks constantly weave in and out of the present. In fact, the short story opens up with one such flashback, a "bright day on the beach at Port Stanley," forty-four years back in time, when a young Fiona proposed to Grant almost jokingly:

"Do you think it would be fun -" Fiona shouted. "Do you think it would be fun if we got married?"

He took her up on it, he shouted yes. He wanted never to be away from her. She had the spark of life. (2010: 448)

Polley tries to mirror Munro's disruptive chronology by resorting to a wide range of cinematic devices, the dissolve technique very prominently amongst them. The film starts with an image of white-haired Grant, in the present tense of the diegesis, driving his car through a suburban area and consulting what seems to be an address written on a piece of paper. Just a few seconds after this, the shot dissolves into a close-up of Fiona's face as an adolescent, radiantly smiling to the camera in what is made to look like an old $8 \mathrm{~mm}$ celluloid. Looking into the camera, she mumbles some words during a series of repetitive, slow-motioned micro-movements. Following Deleuze's "the affection-image is the close-up, and the close-up is the face..." (1986: 87), this is clearly intended as one of those images of affection in the film. Both the close-up and the micro-movements show that this image has been treated as a face that viewers must keep at the forefront of their minds. As Deleuze asserts,

each time we discover these two poles in something - reflecting surface and intensive micro-movements - we can say that this thing has been treated as 
a face [visage]: it has been envisaged or rather "facefied" [visageifiée], and in turn stares at us [dévisage], it looks at us. (1986: 88)

This image of affection recreates the moment when, barely eighteen years old, she proposed to Grant. Separate times and separate spaces are thus instantly interconnected. Repeated various times in the film, this image of affection seems to be one of Grant's recurrent ways of representing Fiona in his mind. But, at a certain point in the film, Fiona will no longer conform to this image of affection, having moved, as the film's framing of the characters shows, to other spaces of representation.

In the ensuing lines, I would like to show how Polley, in making a feminist adaptation of Munro's text, is moving in two directions at once: closer to her and Away from Her. To do so, she resorts to various cinematographic techniques; one of them is adding new scenes and editing others in order to make them subordinate to her reading of Munro's story. Besides this, she employs cinematographic devices such as the "space-off" and "reversal shots" to render her personal way of reading the story. Though it is true that Polley's scripted dialogue shows a high degree of similarity to Munro's text - nearly a third of the film's dialogue reproduces Munro's text almost verbatim - she knows well that the target medium is a different one: the film. The cryptic nature of the text, riddled with ambiguities and silences in between narrated episodes, makes it all the more difficult to adapt to the big screen. In her process of transference from one medium to the other, she must first make her own exegesis of such silences and vague meanings and translate her personal reading of it into a recognizable film structure.

Little wonder, in "A Reading of Away from Her, Sarah Polley's Adaptation of Alice Munro's Short Story, 'The Bear Came Over the Mountain,'” Agnès Berthin-Scaillet questions the very "translatability" from one code to the other: "is it possible," she wonders, "to cinematize a text with the guessed-at ambiguities it withholds?" (2010).

Polley's adaptation is the best proof that even complex, ambiguous texts such as this can be adapted to the screen. From the opening credits, the film shows that Polley has been working hard on such "guessed-at" ambiguities. Suffice to say that in just a few shots, she manages to cinematize the background history of the couple's lifetime-long attachment. A crane's shot from behind of a man and a woman country-skiing side by side through the ice-covered surface of a vast lake gives way to a travelling of the camera showing parallel tracks on the snow as the couple advances forward. The ensuing shot shows how one of them, Grant, has temporarily left the frame to take a divergent course. The tracks on the snow trace Grant's deviating course. Finally, the third shot depicts them reunited sideby-side again. With this cinematographic device, Polley hints as well to former episodes of the couple's life in which they happened to be on the verge of drifting apart due to Grant's adulterous dalliances with his young students during his former days as a university professor. "This smoothly edited series of shots dissolving into each other," as Berthin-Scaillet aptly concludes, "provides the choreography of the couple's life in common, on a filmic scale" (2010). 


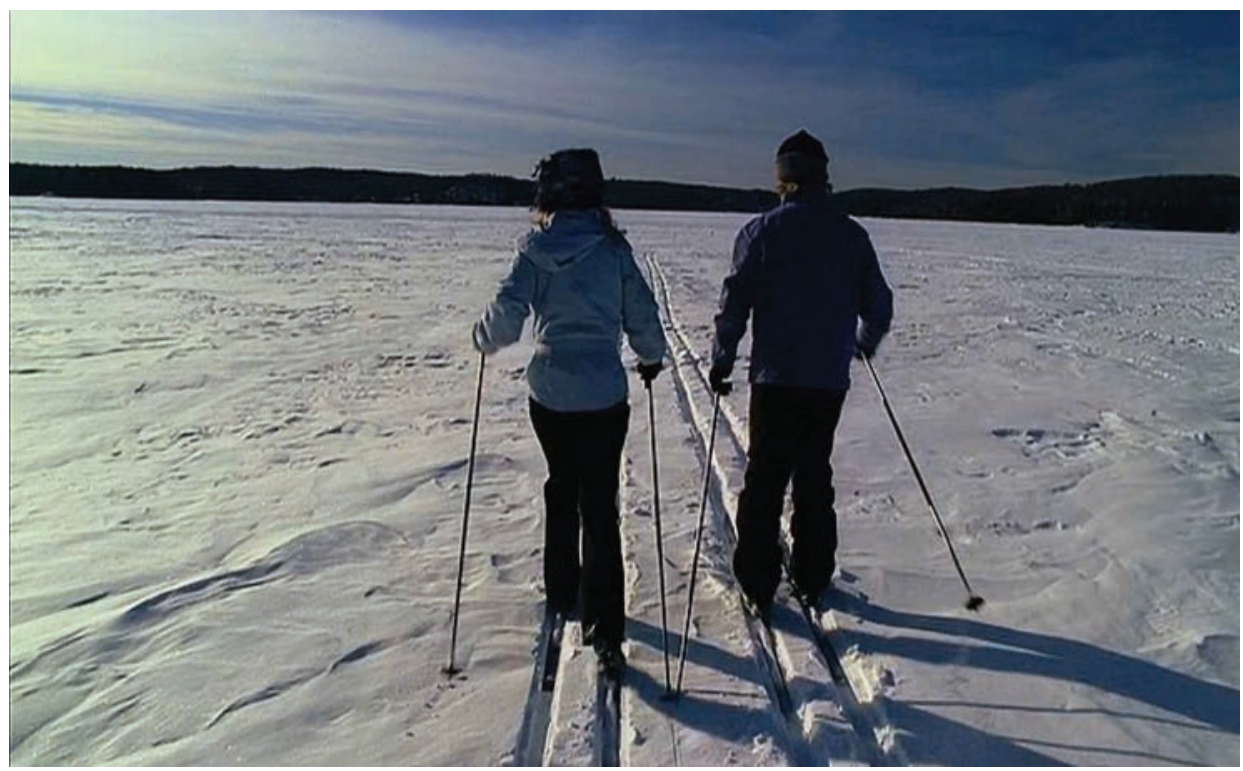

Figure 1. Country-skiing side by side: "a choreography of the couple's life in common, on a filmic scale"

\section{Fiona seems to be gradually succumbing to the ravages of Alzheimer}

Though the dreaded word, Alzheimer, is never mentioned in Munro's story, the Canadian writer depicts a Fiona gradually falling prey to the deteriorating effects of some sort of neurodegenerative disease. Episodes of Fiona's forgetfulness are found in abundance in Munro's short story. In one of them, just to cite an example, Grant notices that Fiona had started to stick yellow notes all over the house. He first attributed this to Fiona's methodical routine, which led her to write down everything.

Even her morning schedule was written down. He found it mystifying and touching in its precision: 7 A.M. Yoga. 7:30-7:45 teeth face hair. 7:45-8:15 walk. 8:15 Grant and breakfast. (2000: 456)

But, to Grant's astonishment, now post-it notes were stuck as well onto kitchen drawers. The notes, clearly meant as a sort of reminder, read: "Cutlery, Dishtowels, Knives" (2000: 112). Why not, he wondered, simply open them to see what is inside? In the film, Polley gives a different spin to this section, when Grant advises her that all the labels and lists may be not doing anything but harming her memory. "If you stop thinking about things the moment you write them down," he warns her, "maybe that's the end of your need to recall." Fiona ominously replies: "If only we recalled just what we needed." Fiona's reply shows that, despite the onset of dementia, her long-term memory remains intact. As 
a sort of needling reminder, she mentions one story, which she claims to have heard from Veronica, one of Grant's former students.

"There was a story I heard once at a dinner party, about the German soldiers on border patrol in Czechoslovakia during the war. Remember that Czech student you had? Veronica? We spoke once at a dinner party." (Polley 2007)

Though Fiona lets this slip casually, the association of ideas, the Czech origin of Grant's student and the story of the German patrol soldiers in Czechoslovakia, is just too pertinent here to be thought fortuitous. At face value, nothing is to be found shocking about this story were it not for the fact that Veronica numbered among Grant's dalliances in his philandering days as a University professor. Noticing that he gets paralyzed as soon as she mentions her name, she smiles and tries to calm his apprehension with soothing words: "Don't get nervous. It's a good story:"

"She told me that each of the German patrol dogs wore a sign that said Hund. Why? said the Czechs, and the Germans said, because that is a Hund." (Polley 2007)

Present in both story and film, such a "Rose is a rose is a rose is a rose" version picks up on the tautological nonsense of the story's title, "The Bear Came Over the Mountain". Most likely, Munro borrowed this title from a popular children's song, "The Bear Went Over the Mountain," often sung to the tune of "For He's a jolly good fellow". ${ }^{4}$ The lyrics of this folksong refer to a bear that sets out on a quest to the other side of a mountain, "to see what he could see." Yet instead of the heroic adventures and surprising discoveries proper of such tales, the only thing he meets is the other side of the mountain, which is, the song tells us, "all that he could see".

Why did Munro choose for her title a variation on a children's self-parodical song? Perhaps because, as Héliane Ventura aptly argues in "The Skald and the Goddess: Reading 'The Bear Came over The Mountain' by Alice Munro," she wanted to blur the frontiers between those who are still on this side of the mountain and those who have gone over the hill only to find themselves on the other side of it (Ventura 2010). Munro clearly questions the ways in which we tend to draw a neat dividing line between sense and non-sense, remembrance and dementia, the world of children and the world of seniors. ${ }^{5}$ The Canadian filmmaker's screen adaptation encapsulates a similar message, thus adhering to Munro's underlying intention. Fiona may be gradually "just going," as she tells Grant, yet her long term memory is far from gone: first, she is capable of remembering episodes of the distant past as vividly as if they had taken place the day before. On their way to Meadowlake, the resident care facility which is to become her new abode, Fiona suddenly recalls, while driving through a nature preserve, the yellow skunk lilies they had once discovered in one of their walking 
tours around the area; second, and harkening back to Polley's screen readjustment of the "Hund" story, this scene is just too intentionally-driven to be easily overlooked. Whereas in Munro's text Grant is the one that recalls the story of the German patrol officers - "He remembered a story about the German soldiers on border patrol in Czechoslovakia during the war" - (2010: 449), in the film Polley chooses to shift focus and reinvent this as Fiona's dose of bitter medicine to her husband for his dalliances in the past. Put more bluntly, Fiona may have intended this as a reminder that, though she may be gradually losing her moorings, her long-term memory has not vanished yet. Overall, while Polley films numerous scenes staging the onset and advance of Fiona's dementia, it is also true that in some cases, such as the ones above, she chooses to set them against the backdrop of Fiona's sound memory for specific episodes of the distant past, Grant's affairs in his days as a university professor not exempted amongst them.

In Munro's story, Grant at times has fears that Fiona's condition may be deteriorating faster than he thought. "Does she even know who I am?" (2010: 459), he is compelled to ask Kristy, the managing nurse. Yet at other times, Grant has serious misgivings about Fiona's about-face and starts to wonder whether she may not be just masquerading, putting on a show to punish him for his infidelities of the past, as "if it was a pretense" (2010: 450). A similar ambiguity is preserved in the film; Christie's superb performance, which gives nothing away, manages to keep the ambiguity alive until the end of the film. As happens in the story, the frontiers between sense and non-sense are likewise shown in the film to be too hazy to discern at which point one has fully crossed the line to the other side of the mountain.

This is not to say, however, that this actress-turned-filmmaker is veering towards filming an exact replica of the story. Far from it, though Polley may faithfully reproduce many of Fiona's lacunae, she also adds new ones or edits others to enhance their melodramatic force on the screen. For instance, barely a few minutes into the film, she includes a scene of her own invention, yet one that clearly points to the possibility that Fiona might be beginning to suffer the symptoms of dementia.

After dinner, Fiona and Grant are cleaning the kitchen together. Grant, who is washing the dishes, hands her a frying pan to be put back in its place. Fiona looks at it in half-astonishment, as if the frying pan were some strange, otherworldly object. After a few seconds, she goes to the freezer, opens its door and puts the frying pan inside. Grant witnesses this with a mixture of awe and condescension. She turns around, and they exchange glances. Fiona's gaze is somewhat nondescript and apologetic, as if she knew that something had gone wrong again, but, alas, couldn't guess exactly what.

Another dinner, this time a dinner party, gives way to one of the most poignant scenes of the film. The camera offers us a medium shot of Fiona, Grant and two other guests exchanging banal pleasantries over a dinner table. Standing up from the table, Fiona picks up a bottle of wine and holds it in her hand to offer some more to the others. "Would anyone like some more...?" The camera zooms over 
her as she is despairingly groping for the word "wine': the only words she can call to mind are but near resemblances: "ween" ... "wane". The scene is heartbreaking enough to make the viewer instantly empathize with Fiona's plight. "I think I may be beginning to disappear," says Fiona in a matter-of-fact, low tone of voice. Her words, however, are followed by an uncomfortable silence that seems to last for eons.

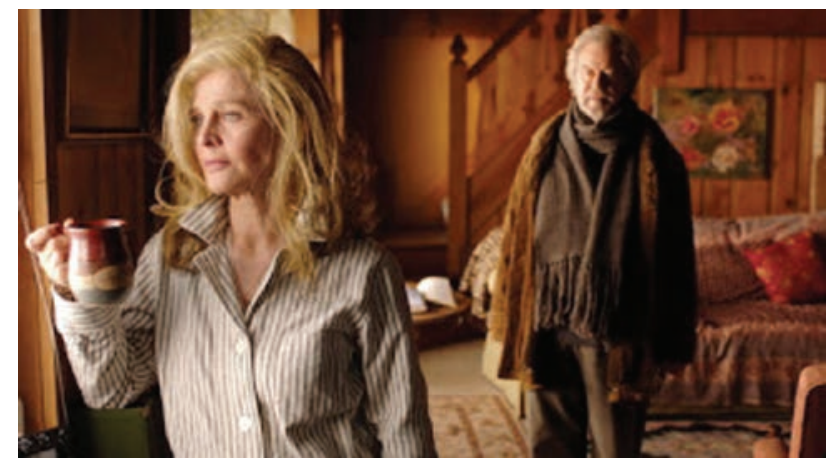

Figure 2. Fiona to Grant: "I think I may be beginning to disappear"

Neither of these two passages cited above, the one with the frying pan and the "ween" scene during the dinner party, was ever mentioned in Munro's story. It would be unfair, however, to say here that Polley is deviating from Munro's text. On the contrary, she seems intent on highlighting those episodes dealing with the onset of dementia so as to enhance their melodramatic effect on the screen. Polley seems to know how to tiptoe through melodrama and to do so wisely eschewing some of the clichés of Hollywood's tearjerkers. In her role as Fiona, Julie Christie avoids the temptation to overact or oversentimentalize. In fact, her performance comes off so naturally that it makes it very difficult to label this film as a Hollywood-styled classic melodrama.

In her adaptation of Munro's text, the Canadian filmmaker not only invents new episodes but she also edits others to suit her own needs. Among the passages she revises is the one in which Fiona gets lost in the woods when she goes alone for a walk across the field. In Munro's short story, Fiona tries to get back home by the fence line - "she said that she'd counted on fences always taking you somewhere" - (2000: 450). Yet her efforts are to no avail. At the end, she had to phone home from a booth (surprisingly, she remembered her phone number "without any trouble"). "I don't think it's anything to worry about," she tries to calm down a worried Grant, "I expect I'm just losing my mind" (2000: 450).

In the film, however, Polley decides to further dramatize the condition of Fiona's disoriented mind. She thus shoots Fiona going out to ski alone and venturing into the woods, away from her cottage, as if she were looking for something very pertinent. A bird's eye shot of Fiona, lost in the midst of a vast expanse of white covered landscape, visually conveys her condition: she is, as Berthin- 
Scaillet rightly concludes, "trapped in the blankness of her own mind" (2010). Mentally fatigued and at a loss, she finally falls upon the icy ground. The movement of the camera, zooming over her as it circles down from above, adds to the sensation of utter loss. A few hours later, darkness having fallen, Grant finds her alone half-freezing on a bridge. Though she seems not to have recognized him, she agrees to be taken home. The following day, when her mind has somewhat recovered, she asks Grant to take her to a care facility. We are "at that point," she euphemistically acknowledges.

Though Grant is unwilling to separate from Fiona, he accepts, urged by her, to pay a preliminary visit to the facilities. There, he is given a tour around the premises by Madeleine Montpellier (Wendy Crewson), the efficient director of this nursing home. He is shocked to learn that, once Fiona checks in, he won't be allowed to get in touch with her for a period of one month. Experience, the director explains, has taught them that they need some time to get used to their new habitat; receiving visitors during this period of adaptation to their new reality could result in a backlash whereas, "if they have a month to adjust, they end up happy as clams". Madeline's optimism is nonetheless contradicted by their visit to the second floor, the place where they take those who "get more progressed" (another euphemism), that is, those who have lost any form of connection to the world outside of their minds. Grant immediately discards this as an option: "my wife isn't going to the second floor".

\section{The space off}

On the day when she was to check into Meadowlake, Fiona, conscious that in her new place of retirement she will have to be "dressed up" at all times, spruces up and faces her own image in the mirror. A shot/reverse shot series of Fiona asking her husband "How do I look?" is counterpointed by Grant's voice-over comments, "direct and vague, sweet and ironic". The way he represents her doesn't seem to match with how she really views herself. "Is that how I look"? wonders a dejected Fiona. She knows that she is being framed, once more, as an object of his fixed representations of her, an "envisaged" image of affection. As John Berger states: "Men act and women appear. Men look at women. Women watch themselves being looked at" (1972: 42).

In Alice Doesn 't: Feminism, Semiotic, Cinema, semiotician and feminist theorist Teresa de Lauretis yields new insights into the nature of cinema as an apparatus of social representation. Our ways of imagining women in terms of gender, as de Lauretis shows, are greatly determined by a successive series of cinematic representations of women, close-ups of their faces and bodies amongst them, and their concomitant effects upon us as viewers. This happens because every single frame is laden with meaning-effects and invested with ideology. The paradox here is that women have remained both the object and cornerstone of this technology of gender representation, but rarely the agents of such representations. 
As de Lauretis states, women have been traditionally represented in cinema as the specular-image of the male gaze, the "looking glass held up to man" (1984: 15). Postmodern women filmmakers are challenging this canonical framework for "imagining" women by resorting to wide spectrum of cinematographic devices and new techniques of editing. One such device is the "spaceoff," a term designating those spaces that have been discarded and left out of the frame. Rather conspicuously, in both classical and commercial cinema, the space-off is either erased or "recontained and sealed into the image by the cinematic rules of narrativization (first among them, the shot/reverse-shot system)" (Lauretis 1984: 26).

In reaction to classical and commercial cinema, avant-garde cinema has made of the space-off a cinematographic fetish as it were; it has shown that, even when censured, it was always there from the start - if not explicitly visible, inferable from what was contained and what was not contained in the frame; in its process of montage, avant-garde cinema has reconstructed the space-off, including it in the picture of the frame and ostensibly marking it as something "ob-scene".

One showcase of Polley's use of the space-off in Away from Her takes place just before Fiona moves to Meadowlake; a high angle shot frames the couple sleeping in bed. But suddenly, Fiona gets up from the bed and leaves both the room and space of the frame. She has now entered the space-off. The indentation of her head on the pillow, Polley's own cinematographic wink, remains there, sealed into the frame, as a testimony of her former presence.

More instances of "space-off" can be seen during Fiona's stay at her new care facility. Having strictly complied with the policy of the centre, Grant, a bouquet of flowers in his hand, visits Fiona after thirty days of imposed separation. Eager to see her again, he first goes to her room upstairs but when he opens the door she is nowhere to be seen. The space of the room is empty. He then walks down to the dining area looking for her and finds her seated at a table next to Aubrey, a wheelchair-bound, mute resident for whom she has developed a kind of emotional attachment. Aubrey is playing bridge with other residents and Fiona remains close to him merely watching the card game. When she sees Grant appear at a distance, she gets up from the table, more out of courtesy than anything else, and approaches him to say hello. When Grant, the bouquet of flowers still in his hand, comments in a tone of half-astonishment, "you were not there," Fiona wryly replies, "I'm here."

On a symbolical level, Fiona's answer translates her desire not to go on filling in the spaces where Grant had always expected her to be. In what is a form of reversal, Fiona is the one now leaving the space of the frame, just as Grant did at the beginning of the film when the camera panned on the couple as they countryskied side by side. Once again Fiona occupies the space-off, outside the framework of Grant's representations. In occupying the space-off formerly taken by Grant during some specific moments of their life together, Fiona reverses her role and no longer acts as Grant's wife: she treats him like a stranger, offers him some tea as one would with any visitor or common resident, and when Grant insists that 
he would like to have a moment of intimacy with her, she brushes it off as if the proposal came from a nagging suitor: "My, you are persistent." Then, once she has formally taken leave of Grant, she goes back to the table to take care again of Aubrey, who has let the cards drop from his hands. Formerly in need, Fiona is now, curiously enough, the one being needed. This shifting of roles, from dependent wife to caretaker, mirrors one of the running motifs in Munro's earlier fiction: caregiving roles and the complex web of emotions attached to each subject position. "Munro's stories," argues Amelia de Falco in "Caretakers/Caregivers: Economies of Affection in Alice Munro," "consider the impossible position of both caregivers and dependents thrust into relations of care, the resentment and frustration of both being needed and being in need" (2012: 393).

Another thing that has changed too is the economy of affections. Fiona's attachment to Aubrey is to be ascribed, so Fiona says to Grant, to the fact that "he doesn't confuse me at all." Fiona wheels Aubrey around the premises of the care facility and joyfully spends the whole day next to him. "Fiona," Kristy informs Grant, "was making some friends. She was definitely coming out of her shell." Grant's sense of guilt for his former misdeeds leads him to suspect that perhaps Fiona is putting on an act: "Wonder whether she isn't putting on some kind of charade?"

He thinks that this "may be a punishment" for his philandering. As he tells Kristy, en route to Meadowlake, the same day Fiona is due to check in, she reminded Grant of his former dalliances with young female students back in the Sixties. Since he can no longer find her there, where he expected her to be, but elsewhere, outside of the framework of his representations of her as his dependent "wife," he starts to wonder whether Fiona might not be using this "elsewhere" as an alibi. The latter term is of special relevance in this context. In Mythologies, Roland Barthes refers to the alibi as a "spatial term," a strategy devised to locate discourse elsewhere and thus make its intentions appear more naturalized. "In the alibi too," argues Barthes "there is a place which is full and one which is empty, linked by a relation of negative identity: 'I am not where you think I am; I am where you think I am not"' (1972: 133); that is, elsewhere, outside of your presuppositions and assumptions about where and how I should be represented, outside of the spatial coordinates you contemplate for me. This relation of negative identity is precisely what seems to provide Fiona with boundless spaces for self-representation.

As is the case in Munro's fiction, the film story shifts focus and now Grant is the one that seems to be slipping into a regressive spiral. Mistaken for a recalcitrant suitor, a befuddled Grant is now forced to assume a passive, background position: for hours on ends he remains seated on the couch in the dining area, patiently watching how Fiona, Aubrey and other inmates play cards or watch sports on TV. We can find numerous instances in Munro's text showing that Grant is the one that seems to be losing his bearings now. He even acknowledges that he "must look foolish and pathetic and perhaps unhinged" for "trailing around after Fiona and Aubrey" (2000: 466). 
Once again, the limits between sanity and dementia begin to blur. Grant changes his role as we witness an episode of clear reversal. Seeing that Fiona has fallen into a severe depression after Aubrey's departure (he has been taken back home by his wife Marian [Olympia Dukakis], who cannot afford to pay the expenses) Grant goes to visit Aubrey's wife to ask her to return him to Meadowlake. He even agrees to begin an affair with her so as to increase his chances of finally convincing her. Aubrey's return, Grant is fully persuaded, will bring back to Fiona "the spark of life". "His ability to transform from jealous husband to procurer of romance for Fiona," as McGill asserts, "aligns adaptation with love and sets the ground for the affect-laden conception of artistic adaptation that Polley presents in discussing Away from Her" (2008: 100).

This reversal of roles, "from jealous husband to procurer of romance," is cinematized through various shots of the long corridor at the care facility. In one of the first corridor shots, he meets Fiona pushing Aubrey's wheelchair. Aubrey is holding some drawings on his lap. One of these drawings slips to the ground and when Grant picks it up he sees a portrait of Fiona. In the fourth shot of the corridor, the camera offers us a medium shot of an astounded Grant walking away from the dining area, just after discovering, to his own dismay, that Fiona has developed an attachment for one of the residents and has mistaken him for a suitor. In the fifth corridor scene, Grant sees Fiona wheeling Aubrey away from him. As Berthin-Scaillet argues,

From a structural point of view, this is a turning point, a kind of fold, in the series of eight. The character placement and the movement within the frame, right in the middle of the series of repeated shots, stages the reversal the character is faced with: an extreme form of reversal that will lead him in the last sequence but one to walk along the same corridor pushing Aubrey's chair up to Fiona's door. (2010)

\section{Away from Her: a paradigmatic text about adaptation?}

In 'No Nation but Adaptation 'The Bear Came over the Mountain,' Away from Her, and What It Means to Be Faithful," Robert McGill considers Polley's feature film not only a case of screen adaptation of a literary text but also a text about adaptation, and, "by extension, about artistic adaptation." Such meta-adaptive endeavours, he argues, are of paramount importance for a country so sensitive to issues dealing with shaping up a cultural identity of its own design ${ }^{6}$ (2008: 110). This to such an extent that in Canada the concept of "national cinema," as Zöe Druick states, "is often closely linked to nation building" (2010: 164).

In cinematizing a cryptic story by one of Canada's most international writers and managing to capture the essence of the text on the screen, Polley is exploring new territories for artistic adaptation. A form of adaptation that is not merely mimetic but creative, and which manages to reproduce Munro's story in new medium without making it subordinate to the original. 


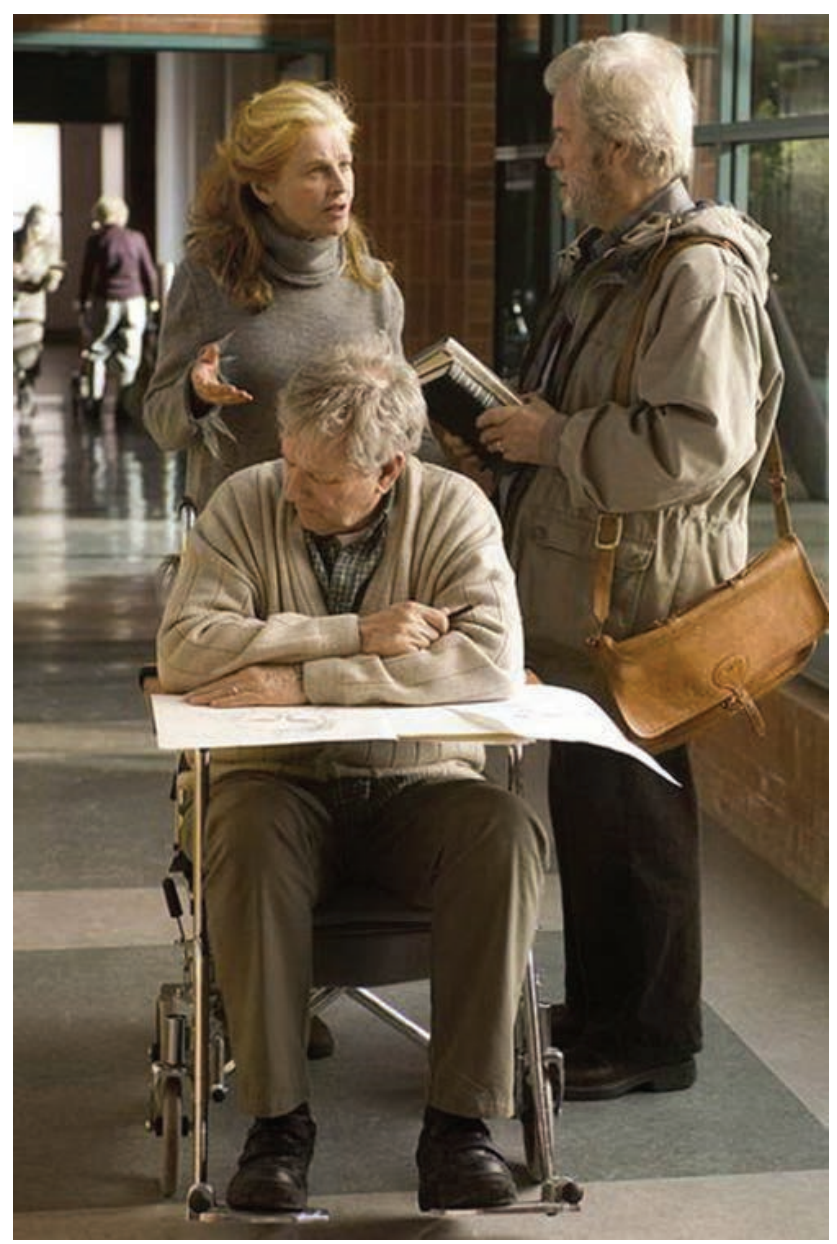

Figure 3. One of the corridor scenes: Aubrey is holding some of his drawings of Fiona on his lap

Polley goes a step further in her adaptation of Munro's text by adding new scenes to her script, such as the frying pan and the "ween" scenes, to further dramatize Fiona's mental lapsus. Yet she juxtaposes these dramatically intense episodes of forgetfulness with others in which Fiona shows that she can still call to her mind some troublesome moments of her distant past, such as Grant's philandering days while he was still teaching at university.

On the other hand, Polley's innovative use of the "space-off" seems to point to a woman-centred interpretation of Munro's story. Once Fiona decides to enter into a care facility, she leaves the space of the frame where she had been represented until now and starts to occupy new spaces of self-representation outside the framework of "dependent wife". Curiously enough, the focus shifts to Grant who seems to be slipping into a regressive spiral of self-identity after he discovers 
that Fiona has developed affection for a resident and takes her own husband for a persistent suitor. Grant is the one who appears to be losing his moorings now for he never knows for certain whether Fiona may not be masquerading to punish him for his former misdeeds. This role-shifting is brilliantly cinematized through the series of repeated shots of the corridor which poeticize, on a filmic dimension, the extreme forms of reversal Grant has to go through: from jealous husband to someone who sacrifices himself to procure her wife's romance with Aubrey. In the wake of Munro's text, Polley's film destabilizes too the frontiers between forgetfulness and remembrance, sense and nonsense, sanity and dementia; yet Polley achieves this by reinventing a cinematographic equivalent of Munro's narrative strategies and filtering the story through the lenses of a feminist reading: Away from Her?

\section{Notes}

1 In Canadian Cinema Since the 1980s: At the Heart of the World, David Pike refers to one of the contradictions which have traditionally affected those Canadian actors who have reached popularity beyond their frontiers: "the more internationally visible an actor becomes, the less Canadian he or she is perceived to be" (2013: 107). However, "one of the consequences of the rise of a new Canadian cinema in the late eighties," Pike argues, "was the emergence of a core of Anglo-Canadian actors who, for the first time, managed to retain their local identity while also crossing over to establish a solid presence in Hollywood." Pike mentions Sarah Polley among them (2013: 107).

2 Curiously enough, Iceland is mentioned on several occasions in Munro's story. Fiona's mother, "a powerful woman with a froth of white hair and indignant far-left politics," (2010: 448) was a native of Iceland. Grant, on the other side, happens to be a professor of Norse mythology. When Fiona moves to a resident care facility, Meadowlake, Grant buys at a local bookstore a "book of nineteenth-century watercolors made by a lady traveller to Iceland" (2010: 469) and takes the book with him to Meadowlake to give it to her as a present.

3 The term "Canadian cinema" is a relatively slippery concept, and so it is advisable to be wary of this whenever one is using this term. A very reliable source to consult possible applications of the term is "Cosmopolitans and Hosers" a chapter included in How Canadians Communicate III: Contexts of Canadian Popular Culture. In this chapter, Zöe Druick describes the concept of 'Canadian cinema' as "polyvalent and context-dependent, referring by turns to a domestic industry, a privileged set of domestically produced 'quality films,' or the actual films watched by various fractions of the national audience" (2010: 164).

4 "The bear went over the mountain/ The bear went over the mountain, / The bear went over the mountain, / To see what he could see. / And what do you think he saw? /And what do you think he saw? / The other side of the mountain, / The other side of the mountain, / The other side of the mountain, / Was all that he could see."

5 In her essay, Ventura provides substantial evidence to prove Munro's blurring of the boundaries between the world of infants and the world of seniors. One example is the name of the Russian wolfhounds owned by the couple: Boris and Natasha. Ventura shows that the names, "which seem to come straight from a Russian novel," are actually taken from "Rocky and his friends," a popular American cartoon of the Sixties. Boris Badenov and Natasha Fatale were the names of two spies. "The obvious puns in the spies' names," Ventura points out, "wittily expose them as 'bad enough' and 'lethal.' In addition to indirect, witty and self-denigrating allusions to children's fictions, Munro also multiplies self-parodic similes which make it possible to erase the difference between the world of children and the world of senior citizens" (2010). 
More concretely, in McGill's own words, “the case of Polley's film speaks to the significance of adaptation for a country which has been preoccupied with building a sense of national cultural heritage" (2008: 110).

\section{References}

Barthes, Roland (1972) Mythologies. New York: Hill and Wang.

Berger, John (1972) Ways Of Seeing. London: Penguin.

Berthin-Scaillet, Agnès (2010) "A Reading of Away from Her, Sarah Polley's adaptation of Alice Munro's short story, 'The Bear Came Over the Mountain." Journal of the Short Story in English 55. Accessed on December 11 2013. http:// jsse.revues.org/index1120.html.

Deleuze, Gilles (1986) Cinema 1. The Movement-Image. Trans. Hugh Tomlison and Barbara Habberjam. Minneapolis: University of Minnesota Press.

Druick, Zöe (2010) "Cosmopolitans and Hosers. Notes On Recent Developments in English-Canadian Cinema." In Beaty, Bart, Derek Briton, Glorial Filax and Rebecca Sullivan (eds.) How Canadians Communicate III: Contexts of Canadian Popular Culture. Athabasca: Athabasca University Press, $161-181$.

Falco, Amelia de (2012) "Caretakers/Caregivers: Economies of Affection in Alice Munro." Twentieth Century Literature 58 (3), 377-398.

Lauretis, Teresa de (1984) Alice Doesn't: Feminism, Semiotics, Cinema. Bloomington: Indiana University Press.

McFarlane, Brian (1996) Novel to Film. An Introduction to the Theory of Adaptation. Oxford: Clarendon Press.

McGill, Robert (2008) "No Nation but Adaptation: 'The Bear Came over the Mountain,' Away from Her, and What It Means to Be Faithful." Canadian Literature 197, Summer, 98-111.

Munro, Alice (1999) “The Bear Came Over the Mountain.” The New Yorker, December 27, 80-127. Munro, Alice (2004) Runaway. New York: Knopf.

Munro, Alice (2010) Alice Munro's Best: Selected Stories. Toronto: McClelland \& Stewart.

Pike, David L. (2013) Canadian Cinema Since the 1980s: At the Heart of the World. Portland: Book News.

Polley, Sarah (2006) Away from Her. Dir. Screenplay by Sarah Polley. Capri Films.

Polley, Sarah (2007) Away from Her. New York: Vintage.

Stone, Alan, A. (2008) “Away From Her”. Psychiatric Times, March, 24-25.

Ventura, Héliane (2010) "The Skald and the Goddess: Reading 'The Bear Came Over the Mountain' by Alice Munro." Journal of the Short Story in English 55. Accessed on November 26, 2013, http://jsse.revues.org/index1121.html.

José Rodríguez Herrera teaches U.S. poetry and drama at the University of Las Palmas de Gran Canaria, Canary Islands. He has devoted much of his research time to study the work of some major U.S. poets. In the year 2013, José Rodríguez Herrera was awarded the SAAS (Spanish Association of American Studies) Biennial Research Award for his article "A Boundary-Dissolving Binding: The Eclectic Composition Underlying the First Edition of Leaves of Grass." Another of his major areas of study is film and literature. "Turkeys 'Bewitched to a Dark Gold' and Licorice Boots: Food and Romance in Charles Chaplin and Francis Scott Fitzgerald," (The Backyard and the US Mansion), is one of his most recent publications within the field of such comparative studies.

Address: José Rodríguez Herrera, Universidad de Las Palmas de Canaria, Edificio de Humanidades, Pérez del Toro, 1, 35003, Las Palmas, Spain. [e-mail: jose.rodriguez@ulpgc.es] 
